\title{
A multistream model of visual word recognition
}

\author{
Philip A. Allen \\ University of Akron, Akron, Ohio \\ Albert F. SMith \\ Cleveland State University, Cleveland, Ohio \\ Mei-Ching Lien \\ Oregon State University, Corvallis, Oregon \\ AND \\ Kevin P. Kaut and Angie Canfield \\ University of Akron, Akron, Ohio
}

\begin{abstract}
Four experiments are reported that test a multistream model of visual word recognition, which associates letter-level and word-level processing channels with three known visual processing streams isolated in macaque monkeys: the magno-dominated (MD) stream, the interblob-dominated (ID) stream, and the blob-dominated (BD) stream (Van Essen \& Anderson, 1995). We show that mixing the color of adjacent letters of words does not result in facilitation of response times or error rates when the spatial-frequency pattern of a whole word is familiar. However, facilitation does occur when the spatial-frequency pattern of a whole word is not familiar. This pattern of results is not due to different luminance levels across the different-colored stimuli and the background because isoluminant displays were used. Also, the mixed-case, mixed-hue facilitation occurred when different display distances were used (Experiments 2 and 3), so this suggests that image normalization can adjust independently of object size differences. Finally, we show that this effect persists in both spaced and unspaced conditions (Experiment 4)-suggesting that inappropriate letter grouping by hue cannot account for these results. These data support a model of visual word recognition in which lower spatial frequencies are processed first in the more rapid MD stream. The slower ID and BD streams may process some lower spatial frequency information in addition to processing higher spatial frequency information, but these channels tend to lose the processing race to recognition unless the letter string is unfamiliar to the MD stream-as with mixed-case presentation.
\end{abstract}

Since the beginning of experimental psychology, researchers have been interested in how humans recognize words during reading. For example, Cattell (1886) hypothesized that words were processed analytically, as component letters, whereas Pillsbury (1897) hypothesized that words were processed holistically, as whole units. Investigators have inferred from the results of many studies that both types of processing are involved (e.g., Rayner \& Pollatsek, 1989). However, few contemporary models of word recognition are based on the physiology of the visual system.

The experiments in this article were motivated by a hybrid model that is an integration of a physiologybased model of the visual system with an informationprocessing model; we call this the multistream model. This model contains a lexicon, the activation of which plays a central role in decisions about whether letter strings are words. However, it differs from most other models of visual word recognition in two important ways: The processing streams of the multistream model analyze spatial frequency information, not visual features; and the different processing channels of the multistream model are responsive to different aspects of the stimulus. That is, letters are not formed from features, and words are not necessarily formed from component letters. Instead, words and letters are formed separately through the use of spatial frequency analysis of different "grain sizes" (i.e., words are recognized from lower spatial frequencies, and letters are recognized from higher spatial frequencies). We elaborate on each of these differences and then describe four experiments in which we tested predictions of the multistream model.

\section{Spatial Frequency Filters Versus Features}

Although many researchers have assumed that perceptual objects (e.g., words) are perceived as collec-

P. A. Allen, paallen@uakron.edu 
tions of features (e.g., Adams, 1979; Coltheart, Rastle, Perry, Langdon, \& Ziegler, 2001; McClelland \& Rumelhart, 1981), two classes of evidence recommend serious consideration of recognition models based on spatial frequency. First, Gervais, Harvey, and Roberts (1984) showed that letter confusions are better predicted by a spatial-frequency model than by a feature model. (We are unaware of any comparisons of a spatial-frequency model with a feature model for whole words.) Second, there is considerable evidence that at least at the retinal and lateral geniculate nucleus (LGN) levels, the visual system uses spatial-frequency filtering rather than features to process visual information (e.g., De Valois \& De Valois, 1990; Van Essen, Anderson, \& Felleman, 1992).

Allen and Emerson (1991; see also Allen, Wallace, \& Weber, 1995) proposed a model of word recognition that assumes that the basic units of visual analysis are the spatial-frequency patterns of whole words and their component letters, respectively. This model is the informationprocessing approach that we integrate into the multistream model.

\section{Cortical Processing Streams in the Primate Brain}

Investigating visual information processing in the macaque, Van Essen and his colleagues have distinguished three cortical processing streams - the magno-dominated (MD) stream, the blob-dominated (BD) stream, and the interblob-dominated (ID) stream (Van Essen \& Anderson, 1995; Van Essen \& DeYoe, 1995). (The BD and ID streams are, collectively, the parvocellular streams.) Recent brainmapping research suggests that the visual cortex of macaques is quite similar to that of humans-particularly in area V1, the origin of these three processing streams (Orban, Van Essen, \& Vanduffel, 2004).

At least two of these three pathways have been studied using physiological (Van Essen \& Anderson, 1995; Van Essen et al., 1992; see also Skottun, 2000, 2001), psychophysiological (Lehmkuhle, Garzia, Turner, Hash, \& Baro, 1993), and brain imaging (Madden et al., 1996; Petersen, Fox, Snyder, \& Raichle, 1990) methods. These studies converge on the following conclusions concerning the characteristic sensitivities of these channels. The MD stream is particularly sensitive to low-spatial-frequency stimuli -0.5 to $1.5 \mathrm{cpd}$ of visual angle (see Legge, Pelli, Rubin, \& Schleske, 1985; Merigan, Byrne, \& Maunsell, 1991; Skottun, 2000) - has a fast conduction rate and responds to luminance differences but is not sensitive to hue differences. The BD stream is sensitive to higher spatialfrequency stimuli ( $>2$ cpd; Legge et al., 1985; Skottun, 2000); has a slow conduction rate; is sensitive to hue, particularly to color contrasts (i.e., to variability in hue within a stimulus); and processes certain brightness, texture, and shape information (Livingstone \& Hubel, 1987; Van Essen \& Anderson, 1995). The ID stream is sensitive to higher spatial-frequency stimuli (again, $>2 \mathrm{cpd}$ ); has a slow conduction rate; and although responsive to hue variability, is less so than the BD stream (Van Essen \& Anderson, 1995). This pathway, too, has been hypothesized to process color, texture, and pattern information (Livingstone \& Hubel, 1987). Table 1 summarizes the processing characteristics of these three streams.

There appears to be considerable overlap in the spatial frequency sensitivity of the magnocellular and parvocellular pathways in the low- to mid-spatial-frequency range (e.g., 1.5-3.5 cpd) (Merigan \& Maunsell, 1993). The key difference between the pathways, then, appears to be conduction rate; the magnocellular pathway has a faster conduction rate than does the parvocellular pathway (Van Essen \& Anderson, 1995).

Peterzell and Teller (2000) examined correlations between contrast sensitivity thresholds across seven levels of spatial frequency $(0.27-2.16 \mathrm{cpd}$ of visual angle) of gratings that were yellow-black (i.e., monochromatic or luminance modulated) and seven levels of spatial frequency of gratings that were red-green (i.e., chromatic modulated). Using principal components analysis with a varimax rotation on the 14 threshold variables, Peterzell and Teller interpreted three principal components as representing a lower spatial-frequency monochrome channel, a higher spatial-frequency monochrome channel, and a chromatic channel (see also Dobkins, Gunther, \& Peterzell, 2000). These channels plausibly correspond to the MD, ID, and BD channels, respectively, of the model of visual processing of Van Essen and Anderson (1995).

Bar (2004) has presented a two-channel model of object and scene processing that has many similarities to the present approach. In this model, there is a fast, lowspatial-frequency channel (involving the magnocellular pathway) that activates global objects and context, and a slower, higher spatial-frequency channel (probably involving the parvocellular pathway) that carries finedetailed information. In many object-identification situations, the faster global (blurry) channel can be used; a "candidate set" of similar perceptual objects is activated, and the selection that results in recognition is made by

Table 1

Characteristics of the Magno-Dominated, Interblob-Dominated, and Blob-Dominated Processing Streams

\begin{tabular}{|c|c|c|c|}
\hline \multirow[b]{3}{*}{ Characteristic } & \multicolumn{3}{|c|}{ Processing Stream } \\
\hline & \multirow{2}{*}{$\begin{array}{c}\text { Magnocellular, } \\
\text { Magno- } \\
\text { Dominated }\end{array}$} & \multicolumn{2}{|c|}{ Parvocellular } \\
\hline & & $\begin{array}{l}\text { Interblob- } \\
\text { Dominated }\end{array}$ & $\begin{array}{c}\text { Blob- } \\
\text { Dominated }\end{array}$ \\
\hline Spatial frequency sensitivity & low frequencies & high frequencies & high frequencies \\
\hline Sensitivity to hue variation & no & no & yes \\
\hline Temporal frequency sensitivity (movement) & high & low & low \\
\hline Conduction rate & fast & slow & slow \\
\hline
\end{tabular}


a top-down contextual module (see Bar, 2004). However, if the global channel cannot recognize an object, detailed information is used by the slower channel. Bar provides magnetoencephalography evidence that suggests that magnocellular activation occurs earlier (at approximately $130 \mathrm{msec}$ after stimulus presentation) than parvocellular activation in object recognition (Bar et al., 2006; Kveraga, Boshyan, \& Bar, 2007). Furthermore, Li, VanRullen, Koch, and Perona (2002) provided evidence that humans can recognize highly familiar global objects (e.g., pictures of animals) in the near absence of attention, but that this is not the case when individual letters or other smaller units are used. The data of Bar and $\mathrm{Li}$ et al. together encourage the idea that a model employing a low-spatial-frequency, global channel and a higher spatial-frequency, analytic channel might be applied to visual word recognition.

\section{The Multistream Model}

The hybrid model of visual word recognition (Allen \& Emerson, 1991; Allen \& Madden, 1990; Allen, Madden, Weber, \& Groth, 1993; Allen et al., 1995; see also Jordan, 1990, 1995; Jordan \& Bevan, 1994, 1996; Jordan, Thomas, Patching, \& Scott-Brown, 2003) postulates a race to a central processor between information in a whole-word channel and that in a component-letter channel; each pathway attempts to use the spatial-frequency pattern of its basic unit of analysis to form a word code, and word recognition is based on information delivered by the channel that wins the race.

There is a natural compatibility among our hybrid model, the two-channel model of Bar (2004), and the Van Essen et al. (1992) three-stream model of cortical pathways; the integrated multistream model is shown in Figure 1. Specifically, the whole-word channel corresponds plausibly to the MD stream, and the component-letter channel corresponds plausibly to the ID and BD streams. In this mapping, the faster MD stream utilizes lower spatial-frequency information. The ID and BD streams utilize higher spatial-frequency information, with the BD stream being particularly sensitive to hue contrasts. Because the processing rates of the BD and ID streams are slower than that of the MD stream, they form word codes more slowly, so information carried by the MD stream typically wins the processing race.

Various data support this hypothesis. Kelly (1979), for example, who investigated the stabilized contrastsensitivity function, found that low-spatial-frequency components (in the magnocellular range) were available before high-spatial-frequency components (in the parvocellular range). Legge et al. (1985) found that the critical spatial-frequency bandwidth for reading was 2 cycles per character and that asymptotic reading rates were achieved with characters of between $0.3^{\circ}$ and $2^{\circ}$, so that processing was optimal with text in the range of $1-6.67 \mathrm{cpd}$. This is in the range of sensitivity of all three streams, but evidence that reading speed increases with blurred text relative to high-contrast text (O’Brien, Mansfield, \& Legge, 2000) suggests that the MD stream is faster at reading than are the ID and BD streams.

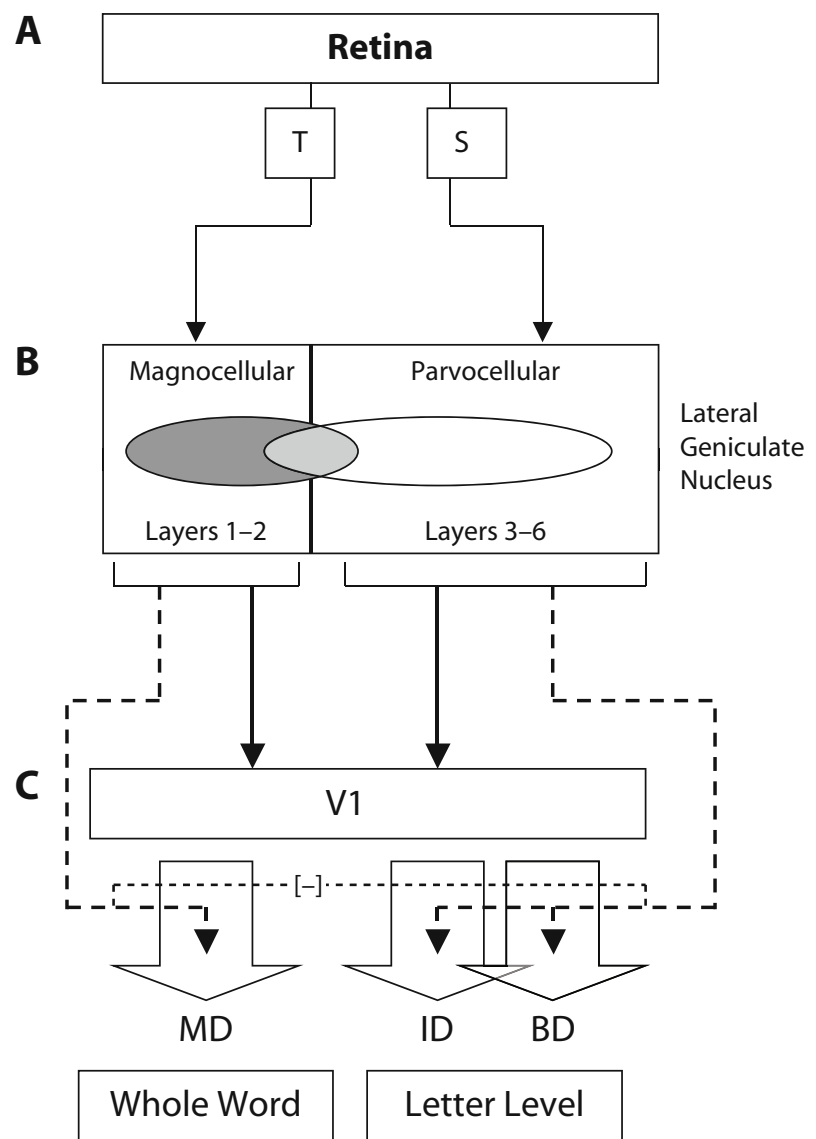

Figure 1. Processing dynamics of the multistream model at three different anatomical levels in the primary visual pathway: $A=$ retinal level, $B=$ lateral geniculate nucleus (LGN) level, and $C=V 1$ (primary visual cortex) level. The transient pathway (T) from the retinae projects primarily to the magnocellular pathway in the LGN. The sustained pathway (S) from the retinae projects primarily to the parvocellular pathway in the LGN. The overlapping of the magnocellular and parvocellular pathways at Level B illustrates that some sustained pathway projections from the retinal level project to the magnocellular LGN layers, even though the vast majority project to the parvocellular layers of the LGN. Likewise, some transient pathway projections from the retinal level project to the parvocellular LGN layers, even though the vast majority project to the magnocellular layers of the LGN. A linkage between brain and psychological levels of representation is illustrated at Level C. Partial LGN activation cascading up to the $\mathrm{V} 1$ level is illustrated by dashed lines, and lateral inhibition at the V1 level is illustrated by dashed lines between MD and ID/ BD. Note that lateral inhibition is assumed to occur only between streams with different LGN pathways (i.e., MD vs. ID or BD, or vice versa, but not ID vs. BD).

\section{OVERVIEW OF EXPERIMENTS}

We report four lexical decision experiments in which we tested predictions of this multistream approach to visual word recognition. The predictions of the multistream model concerned the relative speeds with which experimental participants decide whether letter strings that vary in their composition by color, case, and spacing are words. The predictions were based on assumptions about which of the visual streams carry specific sorts of information and the speeds at which those streams operate. In Experiment 1, 
Table 2

Processing Dynamics for the Present Multistream

Model (in Milliseconds)

\begin{tabular}{lcccc}
\hline & $\begin{array}{c}\text { Magno- } \\
\text { Dominated } \\
\text { (Lowercase) }\end{array}$ & $\begin{array}{c}\text { Interblob- } \\
\text { Dominated } \\
\text { (Mixed Case) }\end{array}$ & $\begin{array}{c}\text { Blob-Dominated } \\
\text { (Just Mixed } \\
\text { Case, Mixed Hue }\end{array}$ & $\begin{array}{c}\text { Faster Output } \\
\text { (Statistical } \\
\text { Facilitation) }\end{array}$ \\
\hline Trial 1 & 400 & 500 & 550 & 500 \\
Trial 2 & 400 & 550 & 500 & 500 \\
Trial 3 & 400 & 500 & 550 & 500 \\
Trial 4 & 400 & 550 & 500 & 500 \\
Mean RT & 400 & 525 & 525 & 500 \\
\hline
\end{tabular}

Note-This illustration of parallel independent statistical facilitation is taken from Raab (1962). Example channel processing times are shown for four trials of each of three word stimulus types - lowercase (the MD channel wins); mixed-case, mixedhue presentation (both ID and BD streams output a code); and mixed-case monochrome presentation (just the ID stream is hypothesized to output a code). If the whole-word stimulus is familiar (e.g., consistent lowercase), the MD stream will typically be used to recognize words rapidly $(400 \mathrm{msec})$. However, if the letter string is presented in mixed case, this would result in an unfamiliar spatial-frequency pattern for the MD stream, but would show familiar patterns for the ID and BD streams, assuming there is a hue contrast necessary for activating the BD stream. When both ID and BD streams output a code and the MD stream is not able to output a code (e.g., mixed-case, mixed-hue presentation), it is assumed that a word will be recognized more rapidly $(500 \mathrm{msec})$ than if just the single ID stream is able to output a code (e.g., for mixed-case monochrome presentation) $(525 \mathrm{msec})$. This advantage of having two parallel, independent, input channels with similar output times operational (both ID and $\mathrm{BD}$ ), relative to having a single input channel operational (ID), provides the theoretical mechanism for predictions made by the multistream model.

we tested the basic model by comparing case type and hue type across words and nonwords. In Experiments 2 and 3, we used a longer stimulus exposure duration $(400 \mathrm{msec}$ instead of $100 \mathrm{msec}$ ) and also varied viewing distance (40 $\mathrm{cm}$ in Experiment 2 and $60 \mathrm{~cm}$ in Experiment 3) in order to determine whether normalization would occur. Finally, in Experiment 4, we replicated Experiment 3, with the added variable of space type (no spaces, spaces).

The stimulus strings used in these experiments were either words or nonwords; in every experiment, participants were instructed to carry out a lexical decision task. For all four experiments, two stimulus characteristics other than stimulus type (i.e., word, nonword) were manipulatedwhether the cases of letters in a stimulus string were all the same or mixed (lowercase and uppercase), and whether the hues of the letters in a stimulus string were all the same (i.e., all red, all green) or mixed (both red and green, intermixed). Within experiments, processing efficiency was compared for strings of the four types yielded by crossing two levels of case consistency with two levels of color consistency. In Experiment 4, we also manipulated spacing: Half of the letter strings were presented with no spaces between letters (e.g., "datum"), and the other half were presented with one space between adjacent letters (e.g., "d a t u m").

We derived two general predictions about visual word recognition from the multistream model. First, we assumed that for same-case words, recognition depends predominantly on information carried by the fast MD stream, whereas for mixed-case strings, recognition depends on information carried by the slower BD and ID streams. From this we predicted that responses to same-case words would be faster or more accurate than those to mixed-case words. Note that this is a common finding in visual word recognition experiments, but one that has been difficult to explain (e.g., Allen et al., 1993; Allen et al., 1995; Carr \& Pollatsek, 1985; Coltheart \& Freeman, 1974; Mayall, Humphreys, \& Olson, 1997). Second, we assumed that mixedcase monochrome strings activate primarily the ID stream that is sensitive to fine detail, but not the BD stream that is sensitive to hue variability, whereas mixed-case, mixedhue strings activate both the ID stream and the BD stream. Taking these assumptions together with the assumption that the BD and ID streams operate at similar rates, we predicted that responses to mixed-case, mixed-hue strings should, on average, be faster than responses to mixed-case monochrome strings. For the former, recognition would depend on information carried by the faster of the $\mathrm{BD}$ and ID streams. Raab (1962) termed this outcome statistical facilitation, in which, when two input channels have similar output times (so that Channel A outputs its code to an output buffer before Channel B outputs its code to an output buffer on some trials, but the opposite occurs on other trials), overall word recognition will be faster when working memory selects the faster of the two (see Table 2).

\section{GENERAL METHOD}

\section{Participants}

Participants were University of Akron undergraduates who participated for research credit. All participants were native speakers of English, reported normal or corrected-to-normal vision, and were screened for red-green color blindness.

\section{Stimulus Materials}

For all experiments, two lists of 384 items, each consisting of 192 words and 192 nonwords, were used. Each set of 192 words included 24 from each of the eight classes that result from crossing four levels of word frequency with two levels of length. The four word-frequency categories, defined by number of occurrences per million in the Kučera and Francis (1967) norms, were very high 
(255-1,702 occurrences per million), medium-high (141-224 occurrences per million), low (40-52 occurrences per million), and very low (1-5 occurrences per million). The two levels of length were five and six letters. From each word, a corresponding nonword was generated by transforming one letter. For example, one fiveletter low-frequency word was "loose"; its corresponding nonword was "loost." We attempted to form nonwords that were orthographically correct, and this was the case for most stimuli. All of these items are presented in the Appendix.

In all of the present experiments, the stimuli were assigned equally often to each of the four conditions. To accomplish this, we divided two sets of 192 words into four groups, each of which contained 6 items from each word frequency $\times$ word length class; the 192 nonwords from the complementary set were similarly divided into groups. For each set of words, the four groups (of 48 words and 48 nonwords) were balanced over the four conditions, so that approximately $25 \%$ of the participants experienced each word group in each experimental condition.

In lowercase strings, all letters were lowercase. In monochrome strings, all letters were either red or green. In mixed-case monochrome strings, in which all letters were either all red or all green, lowercase was assigned at random to each letter, with a probability of half being subject to the constraint that no more than four of the letters be lowercase. Similarly, in mixed-hue strings, red was assigned at random to each letter, with a probability of half being subject to the constraint that no more than four of the letters be red (with the nonred letters all being presented in green). In mixed-case, mixed-hue strings, lowercase and red were assigned randomly and independently to each letter, with a probability of half being subject to the constraints that no more than four letters be lowercase and no more than four letters be red. The purpose of these constraints was, of course, to ensure that mixed strings were actually mixed.

The present approach to constructing mixed-case strings differs, as far as we can tell, from the approaches used by other investigators of this manipulation. Most investigators have used strings in which cases alternate systematically, letter by letter (e.g., MaYaLl \& HuMpHrEyS, 1996; mAyAlL eT aL., 1997), or have assigned cases to letters to systematically encourage or discourage the perceptual grouping of particular letters (e.g., the "pig" in "SpRiNg;" Humphreys, Mayall, \& Cooper, 2003). Experiment 4 of this article addressed the latter possibility.

\section{Stimulus Display and Response Collection}

Personal computers equipped with noninterlaced monitors were used to collect data. Stimulus presentation and timing were controlled by Micro Experimental Laboratory software (Schneider, 1988). The participants responded by using the index and middle fingers of their right hands to operate the left and right arrow keys located in the lower right-hand corner of the keyboard.

The participants sat approximately $60 \mathrm{~cm}$ from the display monitor in Experiment 1. In Experiment 2, participants placed their chins in a chinrest that was positioned $40 \mathrm{~cm}$ from the display monitor. In Experiments 3 and 4, participants placed their chins in a chinrest that was positioned $60 \mathrm{~cm}$ from the display monitor. All stimulus strings were centered on a black background. At a viewing distance of $60 \mathrm{~cm}$, the visual angle subtended by a six-letter string was $1.90^{\circ}$, horizontally. At a viewing distance of $40 \mathrm{~cm}$, the horizontal visual angle was $2.86^{\circ}$.

In all four experiments, the luminances of all stimuli and backgrounds were the same: The red stimulus letters were $48 \mathrm{~cd} / \mathrm{m}^{2}(\mathrm{R}=$ $63, \mathrm{G}=12, \mathrm{~B}=63)$, the green stimulus letters were $48 \mathrm{~cd} / \mathrm{m}^{2}(\mathrm{R}=0$, $\mathrm{G}=50, \mathrm{~B}=0)$, and the gray background was $48 \mathrm{~cd} / \mathrm{m}^{2}(\mathrm{R}=48$, $\mathrm{G}=47, \mathrm{~B}=42$ ). Michelson contrast values in all conditions were 0 .

\section{Procedure}

For each presented item, participants were to respond "word" if the letter string was an English word and "nonword" otherwise; Allen, Smith, Lien, Grabbe, and Murphy (2005) and Allen, Smith, Lien, Weber, and Madden (1997) showed that typical college students knew most of even the very low frequency words. Responses were to be made as rapidly as possible while maintaining accuracy. Stimuli were presented for $100 \mathrm{msec}$ in Experiment 1 and $400 \mathrm{msec}$ in Experiments 2-4. Response time (RT) was measured from stimulus onset to the participant's press of a response key. The assignment of responses to response keys was balanced across participants.

\section{Data Analysis}

In each experiment, we excluded from analyses of RTs trials on which the RT was less than $100 \mathrm{msec}$ or greater than $3,000 \mathrm{msec}$. This resulted in the exclusion of less than $1 \%$ of trials. These trials were treated as errors.

As our primary predictions concerned responses to words, the results of each experiment are reported in two sections: The first concerns responses to words, and the second concerns overall differences between responses to words and nonwords and responses to nonwords.

\section{EXPERIMENT 1}

Experiment 1 was designed to evaluate both of the main predictions of the basic multistream model: Samecase words should be recognized faster than mixed-case words; and for mixed-case words (but not for lowercase words), hue mixing should improve performance relative to monochrome presentation. The hybrid model postulates that the lowercase monochrome and lowercase mixed-hue items are processed by the MD stream, that the mixedcase monochrome items are processed by the ID stream, and that the mixed-case, mixed-hue items are processed by either or both of the BD and ID streams. Although the $\mathrm{BD}$ and ID streams have similar processing rates, RTs for mixed-case, mixed-hue words should depend on the faster of the BD and ID streams, and so responses to these items should, on average, be faster than responses to mixed-case monochrome words (see Raab, 1962).

Alternatively, if words are always formed using a single orthographic input channel - that is, if words are always formed from component letters (see, e.g., Coltheart et al., 2001; McClelland \& Rumelhart, 1981) - then the effect of hue consistency should be the same for lowercase and mixed-case words.

\section{Method}

\section{Participants}

Twenty individuals participated.

\section{Stimuli and Procedure}

Four stimulus conditions were defined by whether stimulus strings were lowercase or mixed case and by whether they were monochrome (either all green or all red letters) or mixed red and green. These two stimulus characteristics were combined orthogonally. As described in the General Method, each stimulus was used in each of the four stimulus conditions: Each of the two 384-item stimulus sets described in the General Method-each consisting of 192 words and 192 nonwords - was divided into four groups of 96 items each; these were counterbalanced approximately across the four conditions (i.e., over participants, each word string was used in each of the four huetype $\times$ case-type conditions). For any given participant, monochrome strings were all red or all green; this was balanced over participants.

\section{Results}

Table 3 shows mean RTs and error rates (ERs) for words and nonwords in each of the four stimulus conditions. 
Table 3

Mean Response Times (RTs, in Milliseconds) and Error Rates (\%E) With Standard Deviations in Experiment 1 by Case Consistency (Lowercase, Mixed Case), Hue Consistency (Monochrome, Mixed Hue), and Lexical Type (Words, Nonwords)

\begin{tabular}{|c|c|c|c|c|c|c|c|c|}
\hline \multirow[b]{3}{*}{ Case } & \multicolumn{8}{|c|}{ Hue Type } \\
\hline & \multicolumn{2}{|c|}{$\begin{array}{l}\text { Mono- } \\
\text { chrome }\end{array}$} & \multicolumn{2}{|c|}{$\begin{array}{c}\text { Mixed } \\
\text { Hue }\end{array}$} & \multicolumn{2}{|c|}{$\begin{array}{l}\text { Mono- } \\
\text { chrome }\end{array}$} & \multicolumn{2}{|c|}{$\begin{array}{c}\text { Mixed } \\
\text { Hue }\end{array}$} \\
\hline & RT & $S D$ & RT & $S D$ & $\% \mathrm{E}$ & $S D$ & $\% \mathrm{E}$ & $S D$ \\
\hline \multicolumn{9}{|c|}{ Words } \\
\hline Lowercase & 673 & 120 & 673 & 114 & 10.3 & 5.0 & 10.5 & 5.7 \\
\hline Mixed case & 746 & 134 & 724 & 123 & 19.0 & 10.6 & 17.5 & 12.6 \\
\hline \multicolumn{9}{|c|}{ Nonwords } \\
\hline Lowercase & 782 & 201 & 800 & 177 & 23.6 & 22.1 & 24.5 & 20.7 \\
\hline Mixed case & 784 & 167 & 795 & 168 & 16.1 & 11.5 & 19.2 & 14.7 \\
\hline
\end{tabular}

\section{Word Analyses}

Response times. RTs for lowercase words $(M=$ $673 \mathrm{msec}$ ) were significantly faster than those for mixedcase words $(M=735 \mathrm{msec})[F(1,19)=78.75, p<.001]$. There was also a hue consistency $\times$ case consistency interaction $[F(1,19)=6.65, p<.05]$. To interpret this interaction, we ran separate simple effect analyses for each level of case consistency. For mixed-case words, responses were faster for mixed-hue words $(M=724 \mathrm{msec})$ than for monochrome words $(M=746 \mathrm{msec})[F(1,19)=$ $9.31, p<.01]$. However, for lowercase words, the effect of hue consistency was not significant $[F(1,19)=0.00, p<$ .97], reflecting the equality of RTs for mixed-hue $(M=$ $673 \mathrm{msec})$ and monochrome $(M=673 \mathrm{msec})$ items.

Error rates. ERs showed that participants responded more accurately to lowercase words $(\mathrm{ER}=10.4 \%)$ than to mixed-case words $(\mathrm{ER}=18.2 \%)[F(1,19)=14.22, p<$ $.001]$. The hue consistency $\times$ case consistency interaction was not statistically significant $(p=.48)$.

\section{Effect of Lexicality and Nonword Analyses}

Response times. RTs for words $(M=704 \mathrm{msec})$ were faster than those for nonwords $(M=790 \mathrm{msec})[F(1,19)=$ $12.96, p<.01]$. There was no hue consistency $\times$ case consistency interaction for nonwords analyzed separately $(p=.66)$. Also, RTs for lowercase nonwords ( $M=$ $791 \mathrm{msec}$ ) did not differ significantly from those for mixed-case nonwords $(M=789 \mathrm{msec})[F(1,19)=0.01$, $p<.90]$.

Error rates. On average, responses to words $(E R=$ $14.3 \%$ ) were significantly more accurate than those to nonwords $(\mathrm{ER}=20.9 \%)[F(1,19)=5.88, p<.05]$. For nonwords, responses to mixed-case strings $(\mathrm{ER}=24.1 \%)$ were more accurate than those to lowercase strings $(\mathrm{ER}=$ $17.7 \%)[F(1,19)=6.07, p<.05]$. For nonwords, there was no hue consistency $\times$ case consistency interaction $(p=.43)$.

\section{Discussion}

In Experiment 1, case mixing slowed word recognition relative to lowercase presentation. This is consistent with the idea that lowercase words are recognized on the basis of information carried by the faster MD stream, whereas mixed-case words are recognized on the basis of information carried by the slower ID and BD streams.

The results of this experiment showed a performance advantage for mixed-case, mixed-hue words relative to mixed-case monochrome words. This is most parsimoniously accounted for by statistical facilitation involving the ID and BD processing streams. Case mixing is presumed to prevent the MD (holistic) channel from forming a wordlevel code, so recognition of mixed-case items is presumed to be based on information that is carried by one or both of the BD and ID streams. When a stimulus word that cannot be processed by the MD stream contains both fine-detail information, to which the ID stream is sensitive, and a hue difference at a boundary, to which the BD stream is sensitive, this word should tend to be recognized faster than words processed by just the ID stream. This is precisely the pattern of results observed in Experiment 1.

Note that we employed isoluminant displays in this experiment, so luminance variation cannot account for the processing advantage for mixed-case, mixed-hue stimuli over mixed-case monochrome stimuli. Furthermore, this effect cannot be attributed to particular stimuli, because all stimulus items were used in each of the four stimulus string conditions.

The results of Experiment 1 are consistent with the predictions of the multistream model but not with those of models of visual word recognition, in which words are always formed from component letters (e.g., Coltheart et al., 2001). However, these earlier models could potentially accommodate these data by adding the more elaborate parallel encoding streams proposed here.

\section{EXPERIMENTS 2 AND 3}

One might be concerned that the overall accuracy rate in Experiment 1 was low-only 82\%. Using physically isoluminant stimuli and background makes a lexical decision task challenging, but it is likely that the 100 -msec letter-string presentation duration made the task so difficult that a $90 \%$ accuracy rate was unobtainable. To determine whether the relatively low accuracy rate observed in Experiment 1 was due to the brief exposure duration and whether the hue-consistency and case-consistency effects would be found under higher accuracy conditions, we increased exposure duration from $100 \mathrm{msec}$ to $400 \mathrm{msec}$ in all subsequent experiments.

A key assumption of the multistream model is that the visual system normalizes retinal images in order to overcome the "poverty of the stimulus" (Allen et al., 1995). If this assumption is correct, retinal size should not change the pattern of results obtained in Experiment 1, but increasing viewing distance (thereby decreasing retinal size) should result in overall longer latencies or lower accuracy (due to increased normalization processing relative to the situation in which retinal size is larger). Parish and Sperling (1991) suggested that the absolute spatial frequency of an object was critical in letter discrimination, but the present view is that the spatial frequency relative to the size of the object is the critical factor in visual word recognition. In order to 
test this hypothesis, we used a 40-cm display distance from the participant's eye to the display monitor in Experiment 2 and a $60-\mathrm{cm}$ display distance in Experiment 3.

\section{Method}

\section{Participants}

Twenty individuals participated in Experiment 2, and 16 individuals participated in Experiment 3.

\section{Stimuli and Procedure}

These were the same as in Experiment 1, except that exposure duration for all stimuli was $400 \mathrm{msec}$ (rather than $100 \mathrm{msec}$ ), and a chinrest was used to control viewing distances. In Experiment 2, the viewing distance was $40 \mathrm{~cm}$; in Experiment 3, the viewing distance was $60 \mathrm{~cm}$.

\section{Results}

Table 4 shows mean RTs and ERs for words and nonwords in each of the four stimulus conditions for both Experiments 2 and 3 .

\section{Word Analyses in Experiment 2}

Response times. RTs for lowercase words $(M=$ $626 \mathrm{msec}$ ) were significantly faster than those for mixedcase words $(M=671 \mathrm{msec})[F(1,19)=99.66, p<.001]$. There was also a hue consistency $\times$ case consistency interaction $[F(1,19)=61.86, p<.001]$. To interpret this interaction, we ran separate simple effect analyses by case consistency. For mixed-case words, responses were faster for mixed-hue words $(M=662 \mathrm{msec})$ than for monochrome words $(M=680 \mathrm{msec})[F(1,19)=7.54$, $p<.05]$. However, for lowercase words, the effect of hue consistency was significant $[F(1,19)=9.73, p<.01]$ but in the opposite direction-reflecting longer RTs for mixed-hue $(M=635 \mathrm{msec})$ than for monochrome $(M=$ $617 \mathrm{msec})$ items.

Table 4

Mean Response Times (RTs, in Milliseconds) and Error Rates (\%E) With Standard Deviations in Experiment 2 (40-cm Viewing Distance) and Experiment 3 (60-cm Viewing

Distance) by Case Consistency (Lowercase, Mixed Case), Hue Consistency (Monochrome, Mixed Hue), and Lexical Type (Words, Nonwords)

\begin{tabular}{|c|c|c|c|c|c|c|c|c|}
\hline \multirow[b]{3}{*}{ Case } & \multicolumn{8}{|c|}{ Hue Type } \\
\hline & \multicolumn{2}{|c|}{$\begin{array}{l}\text { Mono- } \\
\text { chrome }\end{array}$} & \multicolumn{2}{|c|}{$\begin{array}{l}\text { Mixed } \\
\text { Hue }\end{array}$} & \multicolumn{2}{|c|}{$\begin{array}{l}\text { Mono- } \\
\text { chrome }\end{array}$} & \multicolumn{2}{|c|}{$\begin{array}{c}\text { Mixed } \\
\text { Hue }\end{array}$} \\
\hline & $\mathrm{RT}$ & $S D$ & RT & $S D$ & $\% \mathrm{E}$ & $S D$ & $\% \mathrm{E}$ & $S D$ \\
\hline \multicolumn{9}{|c|}{ Experiment 2} \\
\hline \multicolumn{9}{|l|}{ Words } \\
\hline Lowercase & 616 & 120 & 635 & 114 & 9.3 & 1.3 & 7.1 & 0.8 \\
\hline Mixed case & 680 & 134 & 662 & 123 & 10.9 & 1.4 & 12.6 & 1.2 \\
\hline \multicolumn{9}{|l|}{ Nonwords } \\
\hline Lowercase & 696 & 201 & 708 & 177 & 11.0 & 1.4 & 10.4 & 1.3 \\
\hline Mixed case & 709 & 167 & 729 & 168 & 7.9 & 1.3 & 10.7 & 1.0 \\
\hline \multicolumn{9}{|c|}{ Experiment 3} \\
\hline \multicolumn{9}{|l|}{ Words } \\
\hline Lowercase & 696 & 120 & 708 & 114 & 7.8 & 1.0 & 8.5 & 0.9 \\
\hline Mixed case & 770 & 134 & 748 & 123 & 10.0 & 1.1 & 11.1 & 1.2 \\
\hline \multicolumn{9}{|l|}{ Nonwords } \\
\hline Lowercase & 774 & 201 & 793 & 177 & 9.9 & 1.1 & 8.6 & 0.9 \\
\hline Mixed case & 811 & 167 & 836 & 168 & 9.6 & 1.1 & 9.0 & 1.2 \\
\hline
\end{tabular}

Error rates. Error rates showed that participants responded more accurately to lowercase words $(\mathrm{ER}=8.2 \%)$ than to mixed-case words $(\mathrm{ER}=11.8 \%)[F(1,19)=13.67$, $p<.01]$. The hue consistency $\times$ case consistency interaction was not statistically significant $(p=.11)$.

\section{Word Analyses in Experiment 3}

Response times. RTs for lowercase words $(M=$ $702 \mathrm{msec}$ ) were significantly faster than those to mixedcase words $(M=759 \mathrm{msec})[F(1,15)=21.95, p<.001]$. There was also a hue consistency $\times$ case consistency interaction $[F(1,15)=10.32, p<.01]$. To interpret this interaction, we ran separate simple effect analyses by case consistency. For mixed-case words, responses were faster for mixed-hue words $(M=748 \mathrm{msec})$ than for monochrome words $(M=770 \mathrm{msec})[F(1,15)=4.64, p<.05]$. However, for lowercase words, the effect of hue consistency was not significant $[F(1,15)=2.03, p=.17]$, reflecting the approximate equality of RTs for mixed-hue $(M=708 \mathrm{msec})$ and monochrome $(M=696 \mathrm{msec})$ items.

Error rates. ERs for lowercase and mixed-case words were not significantly different $[F(1,15)=3.42, p=.08]$. The hue consistency $\times$ case consistency interaction was not statistically significant $(p=.34)$.

\section{Effect of Lexicality and Nonword Analyses in Experiment 2}

Response times. RTs for words $(M=648 \mathrm{msec})$ were faster than those to nonwords $(M=711 \mathrm{msec})[F(1,19)=$ $31.40, p<.001]$. Also, there was a stimulus type (word, nonword $) \times$ case consistency interaction $[F(1,19)=7.47$, $p<.05]$, indicating that there was a larger case-mixing effect for words than for nonwords. There was no hue consistency $\times$ case consistency interaction for nonwords $(p=$ .45). Also, RTs for lowercase nonwords ( $M=702 \mathrm{msec})$ were faster than those for mixed-case nonwords $(M=$ $719 \mathrm{msec})[F(1,19)=5.70, p<.05]$.

Error rates. On average, accuracy of responses to words ( $\mathrm{ER}=9.98 \%)$ was approximately the same as that of responses to nonwords $(\mathrm{ER}=10.0 \%)[F(1,19)=0.00$, $p=.96]$. For nonwords, accuracy of responses to mixedcase strings $(E R=10.7 \%)$ did not differ significantly from that of responses to lowercase strings $(\mathrm{ER}=9.3 \%)$ $(p=.16)$. For nonwords, there was no hue consistency $X$ case consistency interaction $(p=.10)$.

\section{Effect of Lexicality and Nonword Analyses in Experiment 3}

Response times. RTs for words $(M=730 \mathrm{msec})$ were faster than responses to nonwords $(M=803 \mathrm{msec})$ $[F(1,15)=15.79, p<.01]$. Also, there was a stimulus consistency $\times$ hue consistency $\times$ case consistency interaction $[F(1,15)=6.17, p<.05]$, suggesting that the casemixing effect for monochrome nonwords was smaller than the case-mixing effect for words. There was no hue consistency $\times$ case consistency interaction for nonwords $(p=.56)$. Also, lowercase nonwords $(M=783 \mathrm{msec})$ were responded to more rapidly than were mixed-case nonwords $(824 \mathrm{msec})[F(1,15)=27.49, p<.001]$. 
Error rates. On average, accuracy of responses to words $(\mathrm{ER}=9.4 \%)$ did not differ significantly from that of responses to nonwords $(\mathrm{ER}=9.3 \%)[F(1,15)=0.01$, $p=.91]$. For nonwords, there was no main effect for case consistency $(p=.96)$, and there was no hue consistency $\times$ case consistency interaction $(p=.86)$.

\section{Combined Analyses in Experiments 2 and 3 for Words Only}

Response times. The same pattern of results persisted in the overall analyses as occurred with the separate analyses by experiment. There was a main effect for distance (40 cm, $M=648 \mathrm{msec} ; 60 \mathrm{~cm}, M=730 \mathrm{msec}$ ) $[F(1,34)=17.66, p<.001]$. There was also a main effect for case consistency $[F(1,34)=72.61, p<.001]$, and there was a hue consistency $\times$ case consistency interaction $[F(1,34)=42.43, p<.001]$. The hue consistency $\times$ case consistency $\times$ viewing distance interaction did not reach statistical significance $[F(1,34)=0.03, p=.86]$.

Error rates. There was a main effect for case consistency $[F(1,34)=14.11, p<.001]$, but no other effects reached statistical significance.

\section{Combined Analyses in Experiments 2 and 3 for Nonwords Only}

Response times. There were main effects for distance $[F(1,34)=7.76, p<.01]$ and case consistency $[F(1,34)=$ $29.18, p<.001]$, and there was also a case consistency $\times$ distance interaction $[F(1,34)=4.54, p<.05]$. No other effects reached statistical significance. The case consistency $\times$ distance interaction occurred because there was a larger case-mixing effect at $60 \mathrm{~cm}(M=40 \mathrm{msec})$ than at $40 \mathrm{~cm}(M=17 \mathrm{msec})$.

Error rates. There were no significant effects for the analysis of nonword errors.

\section{Discussion}

The data from both Experiment 2 (40-cm viewing distance) and Experiment 3 (60-cm viewing distance) replicated the core results from Experiment 1: Responses to mixed-case stimuli were slower (and/or were less accurate) than responses to lowercase stimuli, and hue mixing facilitated performance for mixed-case words but not for words (or nonwords) presented in consistent lowercase letters. As was the case for Experiment 1, the stimuli and background were presented at the same luminance levels (physical isoluminance). Thus, these data indicate that there is a small but reliable processing advantage for mixed-case, mixed-hue words relative to mixed-case monochrome words, but that there is no such advantage from mixing hue in lowercase words. We believe that the most parsimonious interpretation of these results is that for lowercase stimuli, lexical decisions are based on output from the more rapid MD processing stream, whereas for mixed-case stimuli, decisions are based on output from the slower parvocellular pathway with its two component streams - the ID stream, which emphasizes details using a grayscale level of analysis, and the BD stream, which emphasizes hue contrasts. For the mixed-case, mixed-hue items condition, both the ID and BD streams are likely to be activated, and statistical fa- cilitation can occur, whereas for mixed-case monochrome items, no hue contrast activates the BD stream, so only one processing channel is activated.

The multistream model also predicts that the MD, ID, and BD streams use normalization to "clean up" ambiguous stimuli for later recognition (or rejection). Whereas the latencies for Experiment 3 (60-cm viewing distance) were significantly longer than the latencies for Experiment 2 (40-cm viewing distance), the data from both experiments showed the same pattern of results across case mixing and hue mixing (i.e., the joint effects were the same). Consequently, these data are consistent with the notion that normalization had occurred (because the visual system had adjusted for retinal size, yet the same pattern of results was obtained), but that more normalization was required for longer viewing distances. Furthermore, these results are consistent with the idea that visual word recognition is based on spatial frequency relative to the size of the object rather than on the absolute object spatial frequency (e.g., Parish \& Sperling, 1991).

\section{EXPERIMENT 4}

An alternative account of the effect of hue consistency on lexical decisions about mixed-case words that was observed in Experiments 1-3 is inappropriate letter grouping (Humphreys et al., 2003; Mayall \& Humphreys, 1996; Mayall et al., 1997). Mayall et al. (1997) manipulated caseconsistency and interletter spacing in stimuli presented in a naming task. In their Experiment 1, in which all stimuli were words, adding spaces between letters did not affect naming times for lowercase words and facilitated naming of alternating-case words. In their Experiment 2, in which both words and nonwords were presented, this pattern was replicated for words and was found for nonwords as well. For their Experiment 3, Mayall et al. (1997) noted that the usual case-mixing manipulation (including that of their Experiments 1 and 2) involved correlated alternation of case and size, and so included stimulus conditions that permitted examination of the separate effects of case mixing (without size mixing) and size mixing (without case mixing). Mayall et al. (1997) found that the disruption in performance with correlated mixing of case and size more than exceeded the separate disruptive effects of case mixing and size mixing. Examining just those stimulus conditions also found in their Experiment 2, the effect of spacing on words was replicated (facilitation of naming for mixed-case, but not for lowercase, words), although the pattern for nonwords was rather different (apparent slowing of naming of lowercase items by spacing, and no effect of spacing on mixed-case items).

Mayall et al. (1997) argued that the most parsimonious account of the case-mixing effect was inappropriate letter grouping: that letters in mixed-case strings that shared case (and size) were grouped perceptually, that this grouping interfered with performance, and that spacing - at least for words - undid this grouping, and with it the deleterious consequences of case mixing for performance.

The pattern of results of Mayall et al. (1997) is superficially similar to the pattern of results that we found for 
hue mixing in lowercase and mixed-case strings. If inappropriate letter grouping is, in fact, the correct account of the results of Mayall et al. (1997), one might suppose that inappropriate letter grouping also adequately accounts for our results. However, it is not clear how this view would account for the different effects of hue mixing on lowercase and mixed-case words observed in the present experiments. If hue is a sufficiently powerful stimulus variable for ungrouping inappropriate letter groups in mixed-case strings, it seems that it should also be sufficiently powerful for subserving the formation of inappropriate letter groups in lowercase strings, thereby slowing performance. This did not occur in the first three experiments of our investigation.

In another pertinent study, Humphreys et al. (2003) varied the case and hue of letters within words and nonwords to determine the effect this had on the naming of "buried" or "embedded" words in which hue was mixed (e.g., "pig" in "spring," "SpRiNg," or "sPrInG"). Case mixing slowed whole-word naming but facilitated the naming of buried words that were presented in different hues (e.g., "p," "i," and "g" might be presented in red, and "s," "r," and " $\mathrm{n}$ " in green). Humphreys et al. concluded that case mixing impairs supraletter grouping (Mayall et al., 1997) and that case mixing facilitates the allocation of attention to subparts of words.

To address the inappropriate letter grouping account of the mixed-case, mixed-hue processing advantage observed in our Experiments 1-3, in the present Experiment 4 we added a spacing variable. For half of the trials, stimulus strings were unspaced, and for the other half, strings were spaced by adding a space between adjacent letters. If the case consistency $\times$ hue consistency interactions observed in Experiments 1-3 were the result of inappropriate letter grouping, this interaction should be attenuated or eliminated in the spaced condition relative to the unspaced condition. Alternatively, the prediction derived from the multistream model is that the same case consistency $\times$ hue consistency interaction should occur at each level of spacing, although one prediction of the multistream model is that adding spacing should add another level of required normalization, thereby increasing latencies and/or errors.

\section{Method \\ Participants \\ Twenty individuals participated in Experiment 4.}

\section{Stimuli and Procedure}

These were the same as in Experiment 3, except we added a spacing condition. That is, for half of the trials, the stimuli were identical to those employed in Experiment 3 (e.g., "datum"), and for the other half of the trials, a space was inserted between adjacent letters (e.g., "d a t u m"). The viewing distance was $60 \mathrm{~cm}$, controlled by having participants use a chinrest. Over participants, every word and nonword occurred in both spaced and unspaced conditions.

\section{Results}

Table 5 shows mean RTs and error rates for words and nonwords in each of the eight stimulus conditions.

\section{Word Analyses}

Response times. RTs for lowercase words $(M=$ $769 \mathrm{msec}$ ) showed a trend toward being faster than those for mixed-case words $(M=797 \mathrm{msec})[F(1,19)=2.65$, $p=.12]$ (but see error data), and there was no main effect of spacing $[F(1,19)=0.68, p=.42]$. The hue consistency $\times$ case consistency interaction, though, was significant $[F(1,19)=5.91, p<.05]$ (For lowercase monochrome words, $M=765 \mathrm{msec}$; for lowercase mixedhue words, $M=773 \mathrm{msec}$; for mixed-case monochrome words, $M=813 \mathrm{msec}$; for mixed-case, mixed-hue words, $M=780 \mathrm{msec}$.) The hue consistency $\times$ case consistency $\times$ spacing interaction also showed a trend toward significance $(p=.07)$. To interpret these data, we conducted simple-effects analyses at each level of case consistency. For mixed-case words, responses were faster for mixed-hue words $(M=780 \mathrm{msec})$ than for monochrome words $(M=813 \mathrm{msec})[F(1,19)=14.36, p<.01]$; this mixed-hue advantage was significant for both unspaced $[F(1,19)=7.06, p<.05]$ and spaced $[F(1,19)=13.66$, $p<.01]$ words. There was no hue consistency $\times$ spacing interaction $(p=.81)$. However, for lowercase words, the hue consistency $\times$ spacing interaction was significant $[F(1,19)=4.70, p<.05]$. To interpret this interaction, we examined the simple effect of hue consistency at each level of spacing. The effect of hue mixing was not statistically significant in either the spaced $(p=.69)$ or the unspaced $(p=.19)$ conditions. The trend toward a significant threeway interaction occurred because of the lowercase words, not the mixed-case words. For mixed-case words, there was a hue-mixing advantage for both unspaced and spaced trials; for lowercase words, there was a trend toward a mixed-hue disadvantage for unspaced trials, but a trend toward a mixed-hue advantage for spaced trials (see Table 5). Finally, the case mixing $\times$ spacing interaction was not significant $(p=.97)$.

Table 5

Mean Response Times (RTs, in Milliseconds) and Error Rates (\%E) With Standard Deviations in Experiment $4(60-\mathrm{cm}$ Viewing Distance) by Case Consistency (Lowercase, Mixed Case), Hue Consistency (Monochrome, Mixed Hue), Spacing (Spaced, Unspaced), and Lexical Type (Words, Nonwords)

\begin{tabular}{|c|c|c|c|c|c|c|c|c|}
\hline \multirow[b]{3}{*}{ Case } & \multicolumn{8}{|c|}{ Hue Type } \\
\hline & \multicolumn{2}{|c|}{$\begin{array}{l}\text { Mono- } \\
\text { chrome }\end{array}$} & \multicolumn{2}{|c|}{$\begin{array}{l}\text { Mixed } \\
\text { Hue }\end{array}$} & \multicolumn{2}{|c|}{$\begin{array}{l}\text { Mono- } \\
\text { chrome }\end{array}$} & \multicolumn{2}{|c|}{$\begin{array}{l}\text { Mixed } \\
\text { Hue }\end{array}$} \\
\hline & RT & $S D$ & RT & $S D$ & $\% \mathrm{E}$ & $S D$ & $\% \mathrm{E}$ & $S D$ \\
\hline \multicolumn{9}{|c|}{ Unspaced Words } \\
\hline Lowercase & 756 & 90 & 777 & 58 & 8.7 & 1.7 & 7.5 & 1.3 \\
\hline Mixed case & 811 & 85 & 777 & 48 & 10.0 & 2.2 & 10.2 & 1.4 \\
\hline \multicolumn{9}{|c|}{ Spaced Words } \\
\hline Lowercase & 775 & 82 & 769 & 53 & 7.7 & 1.8 & 7.7 & 1.5 \\
\hline Mixed case & 815 & 59 & 784 & 55 & 1.2 & 1.6 & 4.6 & 2.4 \\
\hline \multicolumn{9}{|c|}{ Unspaced Nonwords } \\
\hline Lowercase & 774 & 80 & 787 & 83 & 5.6 & 1.2 & 5.4 & 1.3 \\
\hline Mixed case & 796 & 83 & 810 & 85 & 6.2 & 1.6 & 4.6 & 1.1 \\
\hline \multicolumn{9}{|c|}{ Spaced Nonwords } \\
\hline Lowercase & 793 & 95 & 780 & 80 & 8.1 & 1.8 & 7.1 & 1.5 \\
\hline Mixed case & 815 & 100 & 806 & 78 & 7.3 & 1.8 & 6.2 & 1.1 \\
\hline
\end{tabular}


Error rates. Responses to lowercase words (ER $=$ $7.9 \%$ ) were more accurate than those to mixed-case words $(\mathrm{ER}=11.5 \%)[F(1,19)=8.72, p<.01]$. None of the hue consistency $\times$ case consistency $(p=.31)$, hue consistency $\times$ case consistency $\times$ spacing $(p=.59)$, or case mixing $\times$ spacing $(p=.15)$ interactions was statistically significant.

\section{Effect of Lexicality and Nonword Analyses}

Response times. RTs for words $(M=783 \mathrm{msec})$ were not significantly faster than those to nonwords $(M=$ $792 \mathrm{msec})(p=.41)$. For nonwords, there was neither a hue consistency $\times$ case consistency interaction $(p=$ .77) nor a hue consistency $\times$ case consistency $\times$ spacing interaction $(p=.92)$. RTs for lowercase nonwords $(M=$ $783 \mathrm{msec}$ ) were significantly faster than those for mixedcase nonwords $(M=807 \mathrm{msec})[F(1,19)=5.57, p<.05]$. For the nonwords, there was a hue consistency $\times$ spacing interaction $[F(1,19)=6.04, p<.05]$, but when these data were analyzed further by spacing type, there was no simple effect for hue consistency for either spaced or unspaced nonwords $(p s>.25)$. The unspaced nonwords showed a trend toward a mixed-hue disadvantage, but the spaced nonwords showed a trend toward a mixed-hue advantage (for both lowercase and mixed-case nonwords).

Error rates. Responses to words $(E R=9.7 \%)$ were less accurate than those to nonwords (ER $=6.3 \%)[F(1,19)=$ $14.75, p=.01]$. For nonwords, responses to mixed-case strings were approximately as accurate as responses to lowercase strings ( $p=.49)$, and there was no statistically significant hue consistency $\times$ case consistency interaction $(p=.63)$ or hue consistency $\times$ case consistency $\times$ spacing interaction $(p=.71)$.

\section{Discussion}

The data from Experiment 4 replicated the mixed-hue facilitation results for mixed-case words observed in Experiments 1-3. Indeed, this result was observed for both spaced and unspaced words. These results are inconsistent with an inappropriate letter grouping interpretation (e.g., Humphreys et al., 2003; Mayall et al., 1997), because inserting spaces between letters did not eliminate or attenuate the mixed-case, mixed-hue facilitation (relative to mixed-case monochrome presentation). However, these results are consistent with the predictions of the multistream model. That is, spacing should not appreciably affect hue mixing effects for mixed-case words.

The results of Experiment 4 differed from those of Experiments $1-3$ in that the main effect for case mixing was not significant for RT, although this effect was significant for errors. This suggests that the faster MD stream may have been slowed by the spacing manipulation in Experiment 4 (requiring more normalization for the MD stream), but that it was still more accurate than the slower ID and BD streams.

\section{GENERAL DISCUSSION}

These experiments evaluated a model of human visual word recognition that integrates findings from investiga- tions of macaque visual processing (Van Essen \& Anderson, 1995; Van Essen et al., 1992) with an informationprocessing model (Allen \& Emerson, 1991; see also Allen et al., 1995). Both the neuroscience and behavioral models assume that recognition is based on the spatialfrequency patterns of objects and postulate multiple processing channels. The word-level and letter-level channels of the hybrid model correspond roughly to the MD and ID streams, respectively, of the Van Essen and Anderson model, although, as we hypothesized, the BD stream could analytically process information involving hue contrasts. This combined model was termed the multistream model (see Figure 1).

There are two major differences between this framework and that of such local connectionist models as the dual-route cascaded model (Coltheart et al., 2001; see also McClelland \& Rumelhart, 1981), or such distributed connectionist models as those proposed by Perry, Ziegler, and Zorzi (2007); Plaut, McClelland, Seidenberg, and Patterson (1996); Seidenberg and McClelland (1989); Zorzi, Houghton, and Butterworth (1998). First, in the multistream model, visual analysis is carried out by sets of spatial frequency filters, rather than by a set (or sets) of visual feature detectors. Second, the multistream model proposes multiple streams that process different aspects of the stimulus input, rather than just one stream (or multiple streams that process a single input in different ways).

The evidence presented by Peterzell and Teller (2000), who conducted a principal components analysis on log contrast sensitivities for seven spatial frequency levels of each of monochromatic and chromatic gratings, is consistent with the multistream model. Three principal components were interpreted as a chromatic component; a low-spatialfrequency, achromatic component; and a high-spatialfrequency, achromatic component. These plausibly correspond to the $\mathrm{BD}, \mathrm{MD}$, and ID streams, respectively, that we have argued are the pathways of visual word recognition.

Finally, although the model proposed by Bar (2004) was not designed to account for visual word recognition (but, rather, object recognition in natural scenes), this model includes a neural mechanism for more rapid recognition of highly familiar objects using lower spatial frequency (magnocellular pathway) than for that using higher spatialfrequency information (parvocellular pathway). Research reported by $\mathrm{Li}$ et al. (2002) provides additional evidence of the greater importance of global levels of representation than of local levels of representation in the recognition of animals. (Global recognition of whole animals did not require appreciable focused attention, but recognition of separate features of animals did.)

The experiments reported in the present article were designed to evaluate, using human information-processing methods, two specific predictions of the multistream model: In lexical decision, recognition of same-case words would be faster than recognition of mixed-case words; and for mixed-case words, recognition of words in which the hues of letters were mixed would be faster than recognition of words in which all letters had the same hue. These predictions were motivated by the proposal by Van Essen and Anderson (1995) that the parvocellular channel con- 
sists of two branches - the ID stream and the BD stream, with the ID stream being responsible for processing finedetail information, and the BD stream being responsible for processing stimuli that contain variability in hueand that object recognition is based on the first-arriving information carried by these parvocellular channels (the ID and BD streams) and the magnocellular channel (the MD stream).

In the remainder of this section, we review evidence in favor of the multistream model and discuss alternative accounts of the results we have reported.

\section{Empirical Evidence for the Multistream Model}

In each of Experiments 1-4, lowercase words were recognized significantly faster or more accurately than mixed-case words. This is consistent with the hypothesis that the familiar spatial-frequency patterns of whole words are processed by the faster MD stream and that unfamiliar spatial-frequency patterns are processed by the slower ID (and, perhaps, BD) stream(s). Thus, these data are consistent with the hypothesis that both holistic and analytic perceptual objects are used in visual word recognition (also see Allen et al., 1995).

In each experiment, for lowercase words, hue mixing did not affect performance relative to monochrome presentation, but for mixed-case words, hue mixing improved performance relative to monochrome presentation. This facilitation of responding by hue mixing for mixed-case but not lowercase words is predicted by the multistream model. According to the model, only for mixed-case, mixed-hue words are both parvocellular streams active, and RT depends on the faster of the two parvocellular streams.

In Experiments 1-4, we showed that hue variation is essential to the mixed-case, mixed-hue effect: We mixed hues but controlled luminance so that there was no luminance variation and found the performance advantage for mixed-case, mixed-hue words relative to monochrome words. Therefore, hue variation, and not merely luminance variation, appears essential to the effect; our interpretation is that as assumed by the model, only when there is hue variation are both the ID and BD streams activated.

\section{Inappropriate Letter Grouping}

As noted earlier, Humphreys et al. (2003) and Mayall et al. (1997) proposed that case-mixing effects could be attributed to inappropriate letter grouping. They argued that the most parsimonious account of the case-mixing effect was that letters in mixed-case strings that share case (and size) are grouped perceptually, that this grouping interferes with performance, and that spacing, at least for words, undoes this grouping and with it the deleterious consequences of case mixing for performance. Data from Experiment 4, in which case consistency, hue consistency, and spacing were manipulated factorially, showed that inappropriate letter grouping could not account for the observed mixed-hue advantage for mixed-case stimuli because the effect occurred for both spaced and unspaced words. However, the present multistream approach is consistent with the design assumption of Humphreys et al., that humans encode whole words (at least, up to six to eight letters in length; see Carr \& Pollatsek, 1985) in parallel. Furthermore, we believe that our analytic pathways (the ID and BD streams - in which letter strings are encoded individually, but in parallel) are quite consistent with what Humphreys et al. and Mayall et al. (1997) propose as the single channel. Therefore, the point of disagreement is that we believe that a holistic channel is necessary, whereas Humphreys and colleagues do not. Nevertheless, both approaches share an emphasis on whole-word processing.

\section{Lateral Masking}

Previous investigators of the mixed-case disadvantage in visual word recognition have considered the possibility that it is due to lateral masking of lowercase letters by adjacent uppercase letters (e.g., Mayall et al., 1997). Both Mayall et al. (1997) and Humphreys et al. (2003) concluded that lateral masking could not account for their results. On this point, we agree. The lateral-masking interpretation cannot parsimoniously account for the joint effects of hue mixing and case mixing observed in the experiments reported in this article. Furthermore, the results from Experiment 4, in which the hue facilitation effect for mixed-case (but not lowercase) words was not affected by spacing, seem to be particularly inconsistent with a lateral-masking interpretation. Spacing should have at least attenuated any lateral masking.

\section{Isoluminance}

In many studies of the effect of hue on visual processing, researchers have controlled the luminance levels of all stimuli (e.g., Peterzell \& Teller, 2000; Schiller, Logothetis, \& Charles, 1991). In Experiments 1-4, we used isoluminant stimuli and background and observed the mixed-case, mixed-hue advantage relative to mixed-case monochrome. These results imply that this effect is due not to luminance variation but to hue variation.

Peterzell and Teller (2000) found three latent factors (corresponding to one chromatic and two monochrome channels) that appear to be analogous to the three cortical channels discussed in this article. Furthermore, Peterzell and Teller showed that performance using hue (red, green) isoluminance across seven different spatial frequencies was equivalent to that in three other conditions in which the relative luminance of red and green hues was varied. These results converge with the results of our experiments in supporting the existence of three visual channels for visual perception and word recognition.

However, it should be noted that physical luminance differences and perceived (subjective) luminance differences are not necessarily the same. Indeed, Jordan, Sherman, and Tonkin (2007) have shown that using subjective isoluminance has advantages over physical isoluminance. However, subjective isoluminance almost certainly varies not just across individuals, but also within individuals over time, so it may be that both physical and subjective measures of isoluminance are just approximations. Thus, the physical isoluminance control in the experiments reported in this article provides preliminary evidence that the hue-consistency effect we have observed is not due to luminance differences. Subjective isoluminance could 
potentially provide an even more sensitive test of this possibility.

\section{How Many Channels?}

In this article, we have provided evidence that readers use three channels during visual word recognition. However, other evidence suggests that there may be many more distinct spatial-frequency "bands" that are used during visual word recognition (e.g., Patching \& Jordan, 2005). There is significant overlap between magnocellular and parvocellular pathways in spatial-frequency bandwidth (e.g., the magnocellular pathway extends up to spatial frequencies of $3.5 \mathrm{cpd}$; Merigan \& Maunsell, 1993), so there is no reason that both of these main pathways should not use multiple bands of spatial-frequency channels. The three channels postulated by the multistream model may be just the tip of the iceberg in terms of the actual number of channels used during visual word recognition.

A related potential problem with models of visual word recognition that emphasize magnocellular processing to encode global objects (such as the multistream model) is that there is accumulating evidence that individuals have more perceptual sensitivity to words presented in the 5- to 7-cpd spatial-frequency interval (parvocellular) than to those presented in the 1- to 3.5-cpd spatial-frequency interval (the approximate bandwidth of the magnocellular pathway) (Patching \& Jordan, 2005). It does not appear that this is a major problem for the multistream model, however, because fine visual acuity is not hypothesized to be the forte of the MD pathway. Word recognition takes place over time, and a blurry stimulus can be encoded more rapidly than an object processed using higher spatial frequencies (Bar, 2004). That is, even if individuals have poorer perceptual discrimination of objects presented briefly with a low-spatial-frequency band-pass filter than with a higher spatial-frequency band-pass filter (Patching \& Jordan, 2005), it appears that humans recognize these blurry objects faster than they do the higher spatialfrequency objects (e.g., Bar, 2004).

The reason that theoreticians seem to need the concept of global (holistic) and local (analytic or letter-level) channels involved in something like a stochastic race in which the global channel(s) is (are) biased to win is that global precedence has been observed both in brain-based studies, such as Bar (2004), and in behavioral studies, such as Li et al. (2002) and the present study. The usefulness of the magnocellular/parvocellular distinction is that the magnocellular visual pathway represents objects globally and is much faster than the parvocellular pathway, which represents objects locally. Even if this magnocellular/ parvocellular distinction is not correct, such global precedence phenomena in visual word recognition as casemixing effects, word superiority/inferiority effects (e.g., Healy, 1976; Reicher, 1969; Wheeler, 1970), and the nonmonotonic effect of word frequency found when participants match letters with words (Allen \& Emerson, 1991; Allen \& Madden, 1990) must still be explained. The known channel dynamics of the magnocellular/parvocellular distinction allow us to account for global precedence effects for which there is no other parsimonious explanation. The further extension of these pathways into three cortical channels (MD, ID, BD) allows us to account for the hue consistency and case consistency effects reported in the present article.

\section{Do Models of Visual Word Recognition Need More Routes?}

It is unclear to us how models of visual word recognition that use a single orthographic input channel in which words are formed from component letters (see, e.g., Coltheart et al., 2001; McClelland \& Rumelhart, 1981; Perry et al., 2007) can account for the effects of case and hue mixing that we have reported without elaborating their prelexical mechanisms. Indeed, Mayall, Humphreys, Mechelli, Olson, and Price (2001), in a PET study, concluded that their imaging data were "consistent with the idea that case mixing mainly affects early stages of word recognition, and that increased processing at these early stages may allow normal processing in the later lexical stages involved specifically with language processing" (p. 850). This conclusion is fully consistent with the architecture of the multistream model.

We suggest that a whole-word (or at least multiletter) route and two analytic-input routes are needed. In the dual-route cascaded model of Coltheart et al. (2001) and the more recent connectionist dual-process (CDP+) model of Perry et al. (2007), both the lexical nonsemantic route and the grapheme-to-phoneme route process the same encoded input - the letters of the string, which are encoded in parallel. This is identical to the letter-level or analytical-input channel of the hybrid model (Allen \& Emerson, 1991; Allen et al., 1995) and the parvocellular streams (ID, BD) of the multistream model. Interestingly, the earlier connectionist dual-process model of Zorzi et al. (1998) uses onsets and rimes (multiletter units), but these appear to be formed orthographically from features and component letters. (We suspect that individuals use this sort of multiletter encoding, and it would be interesting in future research to determine how this fared in computational modeling.) Without a holistic MD stream, an analytic, achromatic, fine-detailed stream (ID), and a second analytic stream that is sensitive to variation in hue (in the present model, the BD stream) that allows for statistical facilitation on certain mixed-case conditions, it is unclear how a dual-route or multiroute model of visual word recognition could account for the joint effects of case consistency and hue consistency (as well as spacing) observed in the present experiments.

Whether readers use whole words (up to, say, six to eight letters) or just multiletter units cannot be fully addressed with the present data. However, our results do appear to require that letter-level and either word-level or multiletter-level data be processed in a parallel stochastic race to recognition that is biased toward the holistic channel with familiar words. Indeed, there is not likely to be much functional difference between multiletter units of three or more letters and whole-word units. This is why the model proposed by Humphreys et al. (2003), with its em- 
phasis on whole-word processing, has considerable similarities to the present multistream model. As Humphreys and colleagues have noted, their "PIG in sPrInG" data do not present a serious empirical threat to this type of hybrid model because, "if attention to the buried words is facilitated by case mixing, this may help performance here [in processing smaller words embedded in larger words], but not when the task requires reading at the whole word level” (Humphreys et al., 2003, p. 945).

\section{Evidence for a Response Deadline}

One pattern in the present data that challenges the primarily bottom-up multistream model is that nonwords did not show the same mixed-case, mixed-hue advantage as did words. It is possible that the participants used a response deadline that was frequently reached in classifying nonwords. Grainger and Jacobs (1996) argued that in lexical decision, a response deadline is used in classifying strings as nonwords; in the dual-route cascaded model of Coltheart et al. (2001), the response deadline is variable and is set according to the total amount of activation in the lexicon. Essentially, the response deadline accounts for how strings are classified as nonwords without an exhaustive search of the lexicon: If a string has not been classified as a word by the deadline, it is classified as a nonword. The results of the present experiments are consistent with a model of visual word recognition in which information in three input channels (MD, ID, BD) is in a stochastic race to recognition by a central processing unit; these data provide some evidence of the use of a response deadline to reject nonwords. Specifically, in Experiment 1, the processing disadvantage for RT for mixed-case letter strings was eliminated for nonword stimuli (see Table 3 ). This finding is consistent with the notion that quite different processing dynamics were involved in rejecting the nonwords in the present Experiment 1 than were used to recognize the words. For nonwords, recognition probably never occurred. Instead, these nonword items were rejected as words if they were not recognized before a response deadline passed.

Although the nonword RT data from Experiments 2 and 3 did show a case-mixing effect (suggesting that at least two of the hypothesized channels - the MD and ID - were being used to make nonword decisions), the effect of case mixing in the error data for nonwords was directionally the same as that in the RT data in Experiment 1. Namely, the effect of case mixing on errors was much stronger for words than for nonwords (see Table 4).

The stimulus conditions in Experiment 4 (spacing and case consistency manipulations resulted in just $25 \%$ of the words and nonwords being presented in familiar lowercase letters without spacing) appeared to prevent the use of a deadline procedure (as indicated by the finding that nonword RT was not significantly slower than word $\mathrm{RT}$, and that nonword errors were significantly lower than word errors). Interestingly, the spaced nonwords in Experiment 4 (see Table 5) did show a trend toward a mixedhue advantage for RT (for both lowercase and mixed-case stimuli). These results suggest that when a constant dead- line procedure for nonwords cannot work, because many words will require a response deadline as long as that for nonwords due to high levels of whole-word stimulus unfamiliarity, nonwords may be processed more like words, so that there is evidence of a hue-consistency effect when the whole-word or multiletter MD channel cannot output a code due to lack of stimulus familiarity.

\section{Developmental Effects}

Although younger adults in the present four experiments consistently showed a mixed-case, mixed-hue advantage (relative to mixed-case monochrome presentation) for words, other studies have failed to observe this effect for cognitively healthy older adults (Allen et al., 2002) or for cognitively healthy older adults and older adults diagnosed with the amnestic type of mild cognitive impairment (Bush, Allen, Kaut, \& Ogrocki, 2007). Allen et al. (2002) and Bush et al. used the same stimulus conditions as those used in Experiment 1 of this article. The finding that older adults do not show the same huemixing effects as younger adults suggests that older adults are even more holistically biased than are younger adults (Allen et al., 2002).

\section{Conclusion}

The results of these experiments, along with the work of Bar (2004), Jordan and colleagues (e.g., Jordan et al., 2003), Li et al. (2002), Peterzell and Teller (2000), and Van Essen and colleagues (Van Essen \& Anderson, 1995; Van Essen et al., 1992) support the notion that multiple neural processing streams are involved in a stochastic race toward visual object recognition. The present data suggest that visual word recognition tends to be based on the holistic (MD) channel (Allen et al., 1995; Balota \& Spieler, 1998; Spieler \& Balota, 2000), although recognition can use information from the two analytic channels (ID, BD) if the stimulus information is sufficiently unfamiliar to the MD stream (e.g., for mixed-case stimuli; see also Jordan $\&$ Bevan, 1996). The redundancy of this system presumably serves to greatly increase reliability. If one system fails, another system's output can be used to solve the task at hand.

\section{AUTHOR NOTE}

This research was supported by NIH/NIA Grant AG-09282 to the first author. We thank Tim Jordan, Marco Zorzi, Eric Ruthruff, and Chris Chase for comments on earlier drafts of this article, and Jeremy Grabbe for technical assistance. Correspondence concerning this article should be addressed to P. A. Allen, Department of Psychology, University of Akron, Akron, OH 44325-4301 (e-mail: paallen@uakron.edu).

$$
\text { Note-Accepted by the previous editorial team, }
$$
when Thomas H. Carr was Editor:

\section{REFERENCES}

Adams, M. J. (1979). Models of word recognition. Cognitive Psychology, 11, 133-176.

Allen, P. A., \& Emerson, P. L. (1991). Holism revisited: Evidence for parallel independent word-level and letter-level processors during word recognition. Journal of Experimental Psychology: Human Perception \& Performance, 17, 489-511. 
Allen, P. A., \& Madden, D. J. (1990). Evidence for a parallel input serial analysis model of word processing. Journal of Experimental Psychology: Human Perception \& Performance, 16, 48-64.

Allen, P. A., Madden, D. J., Weber, T. A., \& Groth, K. E. (1993). Influence of age and processing stage on visual word recognition. Psychology \& Aging, 8, 274-282.

Allen, P. A., Smith, A. F., Groth, K. E., Pickle, J. L., Grabbe, J. W., \& MADDEN, D. J. (2002). Differential age effects for case and hue mixing in visual word recognition. Psychology \& Aging, 17, 622-635.

Allen, P. A., Smith, A. F., Lien, M.-C., Grabbe, J., \& Murphy, M. D. (2005). Evidence for an activation locus of the word-frequency effect in lexical decision. Journal of Experimental Psychology: Human Perception \& Performance, 31, 713-721.

Allen, P. A., Smith, A. F., Lien, M.-C., Weber, T. A., \& Madden, D. J. (1997). Word frequency effects at brief exposure durations: Comment on Paap and Johansen (1994). Journal of Experimental Psychology: Human Perception \& Performance, 23, 1792-1797.

Allen, P. A., Wallace, B., \& Weber, T. A. (1995). Influence of case type, word frequency, and exposure duration on visual word recognition. Journal of Experimental Psychology: Human Perception \& Performance, 21, 914-934.

Balota, D. A., \& Spieler, D. H. (1998). The utility of item-level analyses in model evaluation: A reply to Seidenberg and Plaut. Psychological Science, 9, 238-240.

BAR, M. (2004). Visual objects in context. Nature Reviews Neuroscience, 5, 617-629.

Bar, M., Kassam, K. S., Ghuman, A. S., Boshyan, J., Schmid, A. M., Dale, A. M., ET AL. (2006). Top-down facilitation of visual recognition. Proceedings of the National Academy of Sciences, 103, 449-454.

Bush, A. L. H., Allen, P. A., Kaut, K. P., \& Ogrocki, P. K. (2007). Influence of mild cognitive impairment on visual word recognition. Aging, Neuropsychology, \& Cognition, 14, 329-352.

Carr, T. H., \& Pollatsek, A. (1985). Recognizing printed words: A look at current models. In D. Besner, T. G. Waller, \& G. E. MacKinnon (Eds.), Reading research: Advances in theory and practice (Vol. 5, pp. 1-82). San Diego: Academic Press

Cattell, J. M. (1886). The time taken up by cerebral operations. Mind, 11, 220-242.

Coltheart, M., \& Freeman, R. (1974). Case alternation impairs word identification. Bulletin of the Psychonomic Society, 3, 102-104.

Coltheart, M., Rastle, K., Perry, C., Langdon, R., \& Ziegler, J. (2001). DRC: A dual route cascaded model of visual word recognition and reading aloud. Psychological Review, 108, 204-256.

De Valois, R. L., \& De Valois, K. K. (1990). Spatial vision. New York: Oxford University Press.

Dobkins, K. R., Gunther, K. L., \& Peterzell, D. H. (2000). What covariance mechanisms underlie green/red equiluminance, luminance contrast sensitivity and chromatic (green/red) contrast sensitivity? Vision Research, 40, 613-628.

Gervais, M. J., Harvey, L. O., JR., \& Roberts, J. O. (1984). Identification confusions among letters of the alphabet. Journal of Experimental Psychology: Human Perception \& Performance, 10, 655-666.

Grainger, J., \& JACOBS, A. M. (1996). Orthographic processing in visual word recognition: A multiple read-out model. Psychological Review, 103, 518-565.

Healy, A. F. (1976). Detection errors on the word the: Evidence for reading units larger than letters. Journal of Experimental Psychology: Human Perception \& Performance, 2, 235-242.

Humphreys, G. W., Mayall, K., \& Cooper, A. C. G. (2003). The PIG in SPrInG: Evidence on letter grouping from the reading of buried words. Psychonomic Bulletin \& Review, 10, 939-946.

JoRDAN, T. R. (1990). Presenting words without interior letters: Superiority over single letters and influence of postmask boundaries. Journal of Experimental Psychology: Human Perception \& Performance, 16, 893-909.

JORDAN, T. R. (1995). Perceiving exterior letters of words: Differential influences of letter-fragment and non-letter-fragment masks. Journal of Experimental Psychology: Human Perception \& Performance, 21, 512-530.

JORDAN, T. R., \& BEVAN, K. M. (1994). Word superiority over isolated letters: The neglected case of forward masking. Memory \& Cognition, 22, 133-144.
Jordan, T. R., \& BeVAn, K. M. (1996). Position-specific masking and the word-letter phenomenon: Reexamining the evidence from the Reicher-Wheeler paradigm. Journal of Experimental Psychology: Human Perception \& Performance, 22, 1416-1433.

Jordan, T. R., Sherman, S. M., \& TonkIN, R. P. (2007). Constructing isoluminant stimuli for word recognition research: A precautionary study. Behavior Research Methods, 39, 494-501.

Jordan, T. R., Thomas, S. M., Patching, G. R., \& ScotT-Brown, K. C (2003). Assessing the importance of letter pairs in initial, exterior, and interior positions in reading. Journal of Experimental Psychology: Learning, Memory, \& Cognition, 29, 883-893.

Kelly, D. H. (1979). Motion and vision: II. Stabilized spatio-temporal threshold surface. Journal of the Optical Society of America, $\mathbf{6 9}$, 1340-1349.

KuČERA, H., \& FrANCIS, W. N. (1967). Computational analysis of presentday American English. Providence, RI: Brown University Press.

Kveraga, K., Boshyan, J., \& Bar, M. (2007). Magnocellular projections as the trigger of top-down facilitation in recognition. Journal of Neuroscience, 27, 13232-13240.

Legge, G. E., Pelli, D. G., Rubin, G. S., \& Schleske, M. M. (1985). Psychophysics of reading: I. Normal vision. Vision Research, 25, 239252.

Lehmkuhle, S., Garzia, R. P., Turner, L., Hash, T., \& Baro, J. A. (1993). A defective visual pathway in children with reading disability. New England Journal of Medicine, 328, 989-996.

Li, F. F., VanRullen, R., Koch, C., \& Perona, P. (2002). Rapid natural scene categorization in the near absence of attention. Proceedings of the National Academy of Sciences, 99, 9596-9601.

Livingstone, M. S., \& Hubel, D. H. (1987). Psychophysical evidence for separate channels for the perception of form, color, movement, and depth. Journal of Neuroscience, 7, 3416-3468.

Madden, D. J., Turkington, T. G., Coleman, R. E., Provenzale, J. M., DeGrado, T. R., \& Hoffman, J. M. (1996). Adult age differences in regional cerebral blood flow during visual word identification: Evidence from $\mathrm{H}_{2}^{15} \mathrm{O}$ PET. Neurolmage, 3, 127-142.

Mayall, K., \& Humphreys, G. W. (1996). Case mixing and the tasksensitive disruption of lexical processing. Journal of Experimental Psychology: Learning, Memory, \& Cognition, 22, 278-294.

Mayall, K. Humphreys, G. W., Mechelli, A., Olson, A. \& Price, C. J. (2001). The effects of case mixing on word recognition: Evidence from a PET study. Journal of Cognitive Neuroscience, 13, 844-853.

Mayall, K., Humphreys, G. W., \& Olson, A. (1997). Disruption to word or letter processing? The origins of case-mixing effects. Journal of Experimental Psychology: Learning, Memory, \& Cognition, 23, 1275-1286.

McClelland, J. L., \& Rumelhart, D. E. (1981). An interactive activation model of context effects in letter perception: Part 1. An account of basic findings. Psychological Review, 88, 375-407.

Merigan, W. H., Byrne, C. E., \& Maunsell, J. H. R. (1991). Does primate motion perception depend on the magnocellular pathway? Journal of Neuroscience, 11, 3422-3429.

Merigan, W. H., \& Maunsell, J. H. R. (1993). How parallel are the primate visual pathways? Annual Review of Neuroscience, 16, 369-402.

O'Brien, B. A., Mansfield, J. S., \& LegGe, G. E. (2000). The effect of contrast on reading speed in dyslexia. Vision Research, 40, 19211935.

Orban, G. A., Van Essen, D. [C.], \& Vanduffel, W. (2004). Comparative mapping of higher visual areas in monkeys and humans. Trends in Cognitive Sciences, 8, 315-324.

Parish, D. H., \& Sperling, G. (1991). Object spatial frequencies, retinal spatial frequencies, noise, and the efficiency of letter discrimination. Vision Research, 31, 1399-1415.

Patching, G. R., \& JoRdan, T. R. (2005). Assessing the role of different spatial frequencies in word perception by good and poor readers. Memory \& Cognition, 33, 961-971.

Perry, C., Ziegler, J. C., \& Zorzi, M. (2007). Nested incremental modeling in the development of computational theories: The CDP+ model of reading aloud. Psychological Review, 114, 273-315.

Petersen, S. E., Fox, P. T., Snyder, A. Z., \& Raichle, M. E. (1990) Activation of extrastriate and frontal cortical areas by visual words and word-like stimuli. Science, 249, 1041-1044.

Peterzell, D. H., \& Teller, D. Y. (2000). Spatial frequency tuned co- 
variance channels for red-green and luminance-modulated gratings: Psychophysical data from human adults. Vision Research, 40, 417-430.

Pillsbury, W. B. (1897). A study in apperception. American Journal of Psychology, 8, 315-393.

Plaut, D. C., McClelland, J. L., Seidenberg, M. S., \& Patterson, K. (1996). Understanding normal and impaired word reading: Computational principles in quasi-regular domains. Psychological Review, 103, 56-115.

RAAB, D. H. (1962). Statistical facilitation of simple reaction times. Transactions of the New York Academy of Sciences, 24, 574-590.

Rayner, K., \& Pollatsek, A. (1989). The psychology of reading. Englewood Cliffs, NJ: Prentice Hall.

REICHER, G. M. (1969). Perceptual recognition as a function of meaningfulness of stimulus material. Journal of Experimental Psychology, 81, 275-280.

Schiller, P. H., Logothetis, N. K., \& Charles, E. R. (1991). Parallel pathways in the visual system: Their role in perception at isoluminance. Neuropsychologia, 29, 433-441.

SCHNEIDER, W. (1988). Micro Experimental Laboratory: An integrated system for IBM PC compatibles. Behavior Research Methods, Instruments, \& Computers, 20, 206-217.

Seidenberg, M. S., \& McClelland, J. L. (1989). A distributed, developmental model of word recognition and naming. Psychological Review, 96, 523-568.
Skottun, B. C. (2000). The magnocellular deficit theory of dyslexia: The evidence from contrast sensitivity. Vision Research, 40, 111127.

Skottun, B. C. (2001). Is dyslexia caused by a visual deficit? Vision Research, 41, 3069-3070.

SPieler, D. H., \& Balota, D. A. (2000). Factors influencing word naming in younger and older adults. Psychology \& Aging, 15, 225-231.

VAN EsSEN, D. C., \& ANDERSON, C. H. (1995). Information processing strategies and pathways in the primate visual system. In S. F. Zornetzer, J. L. Davis, C. Lau, \& T. McKenna (Eds.), An introduction to neural and electronic networks (2nd ed., pp. 45-76). San Diego: Academic Press.

Van Essen, D. C., Anderson, C. H., \& Felleman, D. J. (1992). Information processing in the primate visual system: An integrated systems perspective. Science, 255, 419-423.

VAN Essen, D. C., \& DeYoe, E. A. (1995). Concurrent processing in the primate visual cortex. In M. S. Gazzaniga (Ed.), The cognitive neurosciences (pp. 383-400). Cambridge, MA: MIT Press.

Wheeler, D. D. (1970). Processes in word recognition. Cognitive Psychology, 1, 59-85.

Zorzi, M., Houghton, G., \& Butterworth, B. (1998). Two routes or one in reading aloud? A connectionist dual-process model. Journal of Experimental Psychology: Human Perception \& Performance, 24, 1131-1161.

\section{APPENDIX}

Word and Nonword Pairs

\begin{tabular}{|c|c|c|c|}
\hline \multicolumn{4}{|c|}{ List A } \\
\hline state/stote & being/deing & people/deople & united/unated \\
\hline right/rught & while/whele & public/pablic & number/nimber \\
\hline white/whate & point/poind & looked/dooked & called/colled \\
\hline sense/sanse & thing/thung & itself/itsalf & church/charch \\
\hline whole/wholt & hands/honds & cannot/bannot & really/seally \\
\hline heard/meard & money/maney & office/offuce & became/becime \\
\hline still/stell & world/wirld & around/arount & little/lottle \\
\hline great/breat & since/sance & course/fourse & system/systim \\
\hline later/loter & given/goven & social/docial & second/secand \\
\hline light/dight & began/bogan & seemed/beemed & family/femily \\
\hline human/homan & times/tumes & across/acruss & either/eithen \\
\hline major/mijor & whose/whase & making/meking & result/resolt \\
\hline party/perty & clear/clead & figure/fogure & modern/madern \\
\hline stood/stoon & leave/deave & ground/bround & nature/noture \\
\hline lines/lunes & sound/tound & report/repart & except/axcept \\
\hline union/enion & basis/bosis & higher/ligher & beyond/beyand \\
\hline makes/mukes & miles/ciles & taking/tiking & county/rounty \\
\hline moral/meral & bring/brang & likely/lokely & wanted/winted \\
\hline front/frant & music/masic & mother/muther & strong/strang \\
\hline child/cheld & total/tetal & needed/geeded & months/manths \\
\hline third/thard & black/blick & person/herson & forces/furces \\
\hline moved/muved & wrote/wrate & walked/malked & indeed/ondeed \\
\hline heart/leart & tried/bried & market/morket & growth/grawth \\
\hline floor/floon & trade/trode & answer/unswer & square/squart \\
\hline grace/gruce & grass/gress & august/augast & create/treate \\
\hline agree/agrel & award/awird & honest/hanest & denied/danied \\
\hline spend/spond & prove/prave & player/pluyer & estate/estite \\
\hline faced/ficed & pilot/palot & forget/farget & screen/screet \\
\hline dozen/dazen & count/bount & minute/manute & surely/sarely \\
\hline begun/bigun & hardy/herdy & widely/wodely & safety/sofety \\
\hline angle/ungle & occur/occun & muscle/mascle & listen/lesten \\
\hline phone/phane & chest/chast & abroad/abroan & breath/preath \\
\hline agent/agint & crowd/prowd & bureau/sureau & handle/hondle \\
\hline reply/deply & prime/prome & liquid/loquid & choose/choise \\
\hline route/soute & plain/plair & pocket/pecket & anyway/unyway \\
\hline skill/skall & rapid/ropid & lovely/lavely & smooth/spooth \\
\hline icing/ocing & adapt/adipt & disarm/diserm & defect/difect \\
\hline
\end{tabular}


APPENDIX (Continued)

\begin{tabular}{|c|c|c|c|}
\hline foggy/figgy & digit/dogit & banter/binter & beacon/meacon \\
\hline canon/canin & stabs/stebs & comply/camply & adhere/adherd \\
\hline badge/bedge & fined/foned & dismay/dosmay & bedlam/badlam \\
\hline facet/ficet & brush/blash & humane/humine & casino/cusino \\
\hline coral/curel & madly/mudly & stripe/strope & nugget/nagget \\
\hline ached/eched & batch/betch & decree/ducree & addict/addect \\
\hline décor/dacor & lofty/lifty & abound/abount & acorns/acerns \\
\hline ether/ethen & stale/stule & sailor/sailon & wolves/wilves \\
\hline filth/falth & nooks/dooks & beckon/backon & ferret/farret \\
\hline inert/inart & crook/prook & caress/curess & parcel/porcel \\
\hline leash/reash & heron/heran & enrich/unrich & scanty/scunty \\
\hline \multicolumn{4}{|c|}{ List B } \\
\hline found/lound & those/thise & before/beford & during/doring \\
\hline small/smill & house/couse & enough/anough & though/shough \\
\hline later/nater & group/groul & things/thungs & toward/soward \\
\hline think/thonk & power/powen & gotten/gatten & within/withen \\
\hline today/foday & words/werds & behind/rehind & action/oction \\
\hline taken/daken & study/stady & change/chonge & street/streed \\
\hline where/whare & never/bever & should/chould & school/schoop \\
\hline place/ploce & sight/dight & almost/almest & always/ilways \\
\hline sight/dight & going/moing & rather/rother & better/botter \\
\hline least/leace & large/narge & turned/hurned & become/recome \\
\hline death/meath & field/rield & having/baving & period/heriod \\
\hline known/knawn & shall/shull & reason/teason & moment/poment \\
\hline voice/voibe & court/mourt & common/dommon & policy/rolicy \\
\hline class/blass & north/nerth & rather/nather & values/calues \\
\hline women/wamen & space/spoce & inside/unside & amount/amound \\
\hline hosts/dosts & hours/nours & passed/passet & island/islond \\
\hline river/siver & doing /loing & polite/polide & simply/samply \\
\hline birth/barth & final/finam & better/retter & effort/affort \\
\hline close/clase & level/lavel & future/foture & living/siving \\
\hline leave/leace & short/chort & return/returb & longer/langer \\
\hline alone/alune & value/falue & coming/boming & recent/lecent \\
\hline brown/brewn & stage/stoge & single/ringle & spirit/sparit \\
\hline terms/tarms & shown/shewn & trying/brying & center/menter \\
\hline story/stery & range/ringe & points/foints & entire/antire \\
\hline chair/chail & opera/apera & burden/barden & nodded/nidded \\
\hline sound/gound & flash/flish & lawyer/dawyer & stream/streal \\
\hline guard/guarb & raise/raist & pounds/lounds & dollar/mollar \\
\hline tired/rired & worse/warse & advice/advoce & strike/strake \\
\hline limit/dimit & royal/noyal & easier/eanier & silent/solent \\
\hline pages/mages & hoped/haped & wisdom/wisdor & atomic/atemic \\
\hline loose/roose & depth/dopth & normal/gormal & burned/curned \\
\hline angry/engry & humor/sumor & mantle/mintle & target/torget \\
\hline boats/loats & enjoy/enjay & aspect/aspoct & symbol/symbel \\
\hline views/piews & drama/drima & native/pative & golden/galden \\
\hline sorry/morry & grown/grewn & mobile/mabile & cousin/rousin \\
\hline brain/brait & trend/trond & visual/fisual & unable/inable \\
\hline mirth/morth & weave/neave & teller/tuller & mingle/mongle \\
\hline flops/fleps & booty/rooty & reflex/meflex & panted/pantel \\
\hline ethic/ethac & salve/malve & portal/partal & staple/stople \\
\hline dined/bined & tapes/lapes & beware/seware & corked/horked \\
\hline canal/canel & renew/fenew & delays/deloys & libido/labido \\
\hline bicep/bicup & cores/jores & calico/halico & bigots/rigots \\
\hline grape/prape & paled/raled & cosmos/casmos & deport/duport \\
\hline plush/plosh & pedal/pidal & hounds/lounds & patron/natron \\
\hline bends/hends & modal $/$ mudal & garter/harter & forage/lorage \\
\hline gusto/gisto & chunk/chank & rustic/rastic & bordel/bardel \\
\hline comma/lomma & fairy/nairy & remake/semake & trance/trence \\
\hline datum/gatum & haunt/baunt & embark/imbark & nectar/noctar \\
\hline
\end{tabular}

(Manuscript received January 12, 2004;

revision accepted for publication September 29, 2008.) 